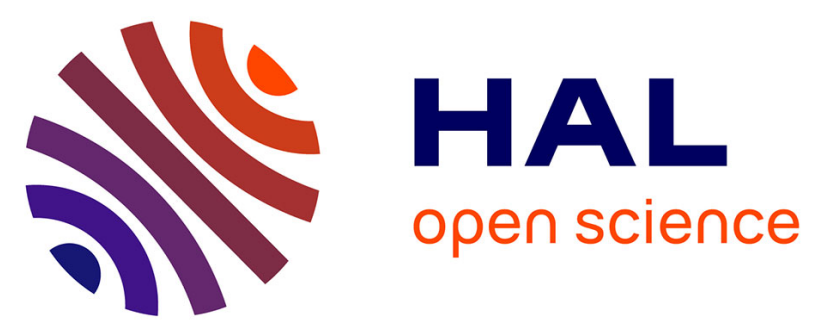

\title{
Sources of uncertainties for total chloride profile measurements in concrete: quantization and impact on probability assessment of corrosion initiation
}

\author{
Stéphanie Bonnet, Franck Schoefs, Manuela Salta
}

\section{- To cite this version:}

Stéphanie Bonnet, Franck Schoefs, Manuela Salta. Sources of uncertainties for total chloride profile measurements in concrete: quantization and impact on probability assessment of corrosion initiation. European Journal of Environmental and Civil Engineering, 2017, pp.1 - 16. 10.1080/19648189.2017.1375997 . hal-01923483

\section{HAL Id: hal-01923483 \\ https://hal.science/hal-01923483}

Submitted on 5 Dec 2018

HAL is a multi-disciplinary open access archive for the deposit and dissemination of scientific research documents, whether they are published or not. The documents may come from teaching and research institutions in France or abroad, or from public or private research centers.
L'archive ouverte pluridisciplinaire HAL, est destinée au dépôt et à la diffusion de documents scientifiques de niveau recherche, publiés ou non, émanant des établissements d'enseignement et de recherche français ou étrangers, des laboratoires publics ou privés. 


\title{
Sources of uncertainties for total chloride profile measurements in concrete: quantization and impact on probability assessment of corrosion initiation
}

\author{
S. Bonnet ${ }^{1}$, F. Schoefs ${ }^{1}$, M. Salta ${ }^{2}$ \\ 1 LUNAM Université, Université de Nantes, GeM, CNRS UMR 6183, Research Institute in \\ Civil Engineering and Mechanics, France \\ 2 Laboratório Nacional de Engenharia Civil, Av. do Brasil, 101, 1700-066 Lisbon, Portugal \\ phone: +33 2409051 03; Fax: +33 2409051 09; \\ E-mail address: stephanie.bonnet@univ-nantes.fr (S. Bonnet).
}

\begin{abstract}
Reliability methods have proved in the past that they were rational aid-tools for the safety assessment of existing structures, within which some uncertainties occurred. Condition assessment is usually carried out using on-site measurements, which are assumed perfect. However, it is now accepted that some significant uncertainties may affect the assessment of material properties using semi-destructive methods. The purpose of this paper is to present a method for the identification and evaluation of measurement uncertainties using a bias and a zero mean error modelled by a random variable. These uncertainties obtained are then modelled using a probabilistic model. In a marine environment, the main cause of reinforced concrete structure degradation is the corrosion due to chloride ingress. The chloride profiles are determined using a destructive method involving many steps where the experimenter plays a key role. In order to identify sources of errors, four researchers have performed repeatability tests. The total chloride content is expected to be the same for all the samples. The heterogeneity has been studied using statistical analysis. A value of the bias is provided and the model results are consistent with the original results. Finally, the impact of measurement errors on reliability and life-cycle assessment is discussed.
\end{abstract}

Keywords: error modelling, laboratory tests, probabilistic modelling, chloride profiles, statistical analysis, probability of corrosion detection, reliability analysis 


\section{Introduction}

During the past three decades, reliability methods have provided efficient rational aid-tools for the safety assessment of new designed concrete structures (Marquez et al. 2012). They have gradually been extended to include the structural reliability assessment of existing structures. Civil engineering offers key challenges in this field because of the cost and difficulty of on-site measurements to evaluate precisely the material degradation. These methods require to identify the uncertainty sources, then to quantify and model them, generally on the basis of statistical studies. The measurements, achieved through Destructive and Non Destructive Testing (NDT) or Structural Health Monitoring (SHM) sensor, are then assumed perfect (Oslakovic, 2010; Yang et al. 2012) except for some works where studies are mainly theoretical (Faber and Sorensen 2002; Rouhan and Schoefs 2003; Sheils et al. 2010 and 2012; Bastidas and Schoefs 2012). However, most of the time, measurement error modelling assessment is not based on real data because no experimental database is currently available. The aim of this paper is to present the findings of the study conducted to identify sources of uncertainties for the measurement of total chloride profiles in concrete. With this aim in view, uncertainties are then modelled using an appropriate probability density function. In a marine environment, indeed, the main cause of reinforced concrete structure degradation is the corrosion of steel rebars because of the presence of chloride ions due to concrete porosity. When the chloride ion concentration reaches a critical value, called $\mathrm{C}_{\text {crit, }}$ the steel bars are not protected anymore and corrosion is initiated. Tuuti proposes a conceptual model dividing the service life of reinforced concrete (RC) structures into two distinct phases: the initiation phase and the propagation phase (Tuuti 1986). The present paper focuses only on the initiation phase through a comparison of the chloride content with the critical chloride level, from which the passivation of steel surfaces becomes unstable. The adoption of corrosion initiation as the limit state to define service life of RC structures has already been challenged by researchers for both saturated and unsaturated concrete (Kong 2002, Val 2008). In this, the most accurate determination of chloride profiles with depth is one of the main issues of structure service life prediction. Non destructive techniques are currently under development in order to detect and quantify corrosion rate and chloride content with good accuracy (Ahmad 2003; Balayssac et al 2011, Montemor et al. 2003, Torres-Luque et al. 2014, Lecieux 2015). These techniques give good results for free chloride content as regards experiments conducted in the laboratory but, as the sensors are affected by many parameters (water content, porosity, cracks, etc.), in situ 
chloride content measurements are still unreliable (Montemor et al. 2006; Atkings et al. 2001). Other techniques are under development to achieve chloride profiles without breaking the concrete specimen (Silva et al. 2012; Wall et al. 2008). Unfortunately, these techniques are costly when the key factors for the choice of the method are precisely cost and time.

For these reasons, the present study focuses only on the total chloride profiles determined using a semi-destructive method because both bound and free chlorides are involved in the corrosion process (Reddy et al. 2002). As regards the problem of distinguishing experimentally between free and bound chloride, some authors consider that the critical chloride content must be compared to the total chloride content (Tuuti 1982, standard 2006). The total chloride profile measurements are commonly used for service life predictions of structures to:

- update the chloride diffusion coefficient used in corrosion prediction models;

- calibrate NDT tools (Kirkpatrick et al. 2002; Liang et al. 2005).

The aim of this paper is to quantify the measurement reliability in providing a rational decision aid-tool for inspection or work planning. With this aim in view, error measurement of total chloride profiles is essential. To our knowledge, no previous experimental works was carried out until now to assess and model the several sources of measurement uncertainties.

This study has been conducted within the context of the European Interreg III B project, called Medachs (http://www.medachs.u-bordeaux1.fr). This research project concerns the durability and maintenance of coastal concrete structures. Specifically, the structure studied at the GeM laboratory is a quayside of the Nantes-Saint-Nazaire harbour (France) built in 1971 and located in the estuary of the Loire River on the Atlantic coast of France. Some profiles of concrete cores extracted from the quay have been analyzed using a probabilistic study, which pinpointed problems relating to the lack of measurement uncertainty model (Rosquoët et al. 2006). The total chloride profiles obtained on field are difficult to analyze with regards to their uncertainty measurement and to the many parameters they are depending on: cement type, environmental parameters and concrete quality and damaging (Ben Fraj et al. 2012; Castro et al. 2001; Costa and Appleton 1999; Djerbi et al. 2008; Lindvall 2007, Sosdean et al 2016). The determination of the chloride profiles, indeed, is a manual procedure (Chaussadent and Arliguie 1999; RILEM 2002; Vennesland et al. 2012), in which the experimenter plays a key role. The profile analysis, therefore, implies that the confidence in the measured values is 
discussed and quantified to be implemented in a rational decision process for maintenance or inspection planning.

It is important to note that chloride transport mechanisms affect the quantity of chlorides with depth but not the assessment procedure and the error on measurement. Moreover, the error is assumed to be independent from the chloride content. This is a common assumption when semi-destructive techniques or NDT without any change in the settings of the NDT tool are used.

This paper initially begins with key issues about uncertainty modelling and about their applications for modelling uncertainty of measurement. A probabilistic modelling of errors (human and protocol) is then presented. How it affects reliability assessment is finally discussed.

In order to quantify the uncertainty of measurement, some repetitive tests have to be carried out on laboratory specimens with a process distinguishing between human and other factors influencing the measurement. Section 3 presents the experimental programme, which leads to error measurements. In Section 4, the modelling of the uncertainty in total chloride content measurements is examined. Finally, the statistical analysis, the probabilistic modelling and the effect of uncertainty in measurements for reliability and life-cycle assessment are discussed. Our main objective is the better understanding of the estimated probabilities that corrosion initiation is detected from on site destructive testing.

\section{Uncertainty of measurement: from identification to modelling}

\subsection{Sources of uncertainties}

Even though the hierarchy of sources of uncertainties in engineering remains an open and controversial question (Der Kiureghian and Ditlevsen 2009), the classification published by Ang and Tang (1978), however, provides a satisfactory framework. This list is divided into two categories of sources of uncertainties: aleatoric and epistemic.

Sources of uncertainties are considered as 'aleatoric' when they come from natural or industrial hazard.

'Epistemic uncertainties' are due to the limitation of human knowledge and modelling of complex reality and are assumed to diminish in the future with the progress of scientific knowledge, the accuracy of protocols and the development of technology. They gather 
various sources like uncertainty of measurement, error due to lack of experience when using a tool and uncertainty of modelling.

Deby et al. (2009) consider the modelling error of the diffusion coefficient by comparing calculated and experimental coefficients: the model must be selected and the error will vary depending on the model. Henceforth, a special focus is placed on the quality of chloride content assessment itself. The objective of this research is to investigate the sources of uncertainties when the total chloride content is measured and to present the results as regards identification, measurement and modelling. The protocol describing the process is discussed in Section 3.

\subsection{Effect on structural reliability and probability of defect assessment}

Measurement errors affect both the computing of structural reliability and the decision through the probability of assessment of the measured property. Let $\hat{R}$ denotes the measured material property (typically a Resistance parameter) and $R$ the real value of the property measured with a perfect tool:

$$
\hat{R}=R+\mathrm{e}_{\mathrm{t}}
$$

where $e_{t}$ is the total measurement error.

When measurement data are directly used for reliability assessment without using a structural model and a complex limit state, the reliability can be assessed simply by estimating the probability of failure, $P_{f}$ as, defined as:

$$
P_{f}=\mathrm{P}\left(\hat{R}>R_{\text {crit }}\right)
$$

where $R_{\text {crit }}$ is the critical value, also called acceptable or limit threshold in Load and Resistance Factor Design (LRFD) method.

Let us consider a non-perfect measurement of $R$. A survey of the literature on the concepts of probability of detection and probability of false alarm reveals that a considerable amount of effort has been devoted to this subject for characterizing the performance of Non Destructive Testing tools (Faber and Sorensen 2002; Rouhan and Schoefs 2003; Sheils et al. 2010). The probability for good assessment, called PGA, is a quantity very useful for decision planning on structural maintenance (Sheils et al. 2010). It is defined by the conditional probability:

$$
P G A=\mathrm{P}\left(\hat{R}>R_{\text {crit }} \mid R>R_{\text {crit }}\right)
$$




\section{Experimental programme}

This section describes the experimental program applied to assess the total error of measurement, $e_{t}(1)$, in the case of total chloride determination in concrete.

\subsection{Concrete mixture and specimen preparation}

The concrete material used for the repetitive tests is made of ordinary Portland cement and limestone filler. The cement type CEM I 52.5N comes from the Saint-Pierre Lacour's plant (France). The chemical composition, provided by the manufacturer, is detailed in Table 1. The density is $3150 \mathrm{~kg} / \mathrm{m}^{3}$ and the specific surface area is $365 \mathrm{~m}^{2} / \mathrm{kg}$.

The limestone filler consisting of $96.8 \%$ of $\mathrm{CaCO}_{3}$ is produced at the Erbray's facility (France). The density and specific surface area are $2696 \mathrm{~kg} / \mathrm{m}^{3}$ and $419 \mathrm{~m} / \mathrm{kg}$, respectively. The 0/4-mm sand is siliceous river sand with a density of $2580 \mathrm{~kg} / \mathrm{m}^{3}$ and a water absorption coefficient of $0.9 \%$ (in mass). The aggregate are 10/14-mm siliceous gravels with a density of $2592 \mathrm{~kg} / \mathrm{m}^{3}$ and a water absorption coefficient of $0.5 \%$ (in mass). Concrete composition is described in Table 2. The Water to Binder ratio W/B is O.47.

Five concrete cylinders with a length of $22 \mathrm{~cm}$ and a diameter of $11 \mathrm{~cm}$ are prepared from a single batch. The concrete is cast in steel moulds and compacted using a mechanical vibrator. After casting, the cylindrical moulds are stored in a humid chamber maintained at $20^{\circ} \mathrm{C}$ with a relative humidity $(\mathrm{RH})$ of about $85 \%$ for 24 hours before demoulding. Then the cylindrical concrete specimens are stored together in the same humid chamber to be well-hydrated. After 28 days, three cylinders are tested under axial compressive loading conditions to obtain the compressive strength. The mean value obtained is $36 \mathrm{MPa}$.

The two other cylinders are kept in the humid chamber during six months then cut into cylinders with a length of $2.5 \mathrm{~cm}$ and a diameter of $11 \mathrm{~cm}$ using the water jet cutting technology. Four specimens, called S1, S2, S3 and S4, are sampled in the middle part of the two cylinders: S1 and S2 from the first cylinder and S3 and S4 from the second one.

All the four specimens are oven-dried at $60^{\circ} \mathrm{C}$ to constant weight. This drying stage lasts five months. Then, the discs are cooled for $48 \mathrm{~h}$ in a desiccator at $20^{\circ} \mathrm{C}$ before being tested. The concrete sample preparation, like cutting or drying for instance, may affect the microstructure of concrete. However, this damaging risk is equally shared by all the concrete samples. 


\subsection{Chloride contamination in concrete}

The objective is to obtain the homogeneous chloride content in the concrete specimens for conducting repetitive tests. Consequently, the chloride content with depth should be the same for all the specimens. The specimens must be in equilibrium with the salted solution.

Three dried samples (S1, S2 and S3) are fully submerged in a container filled with a sodium chloride solution, which is renewed regularly to maintain the desired chloride content in the surrounding solution. This solution combines a $30 \mathrm{~g} / \mathrm{l} \mathrm{NaCl}$ solution closed to the level of $\mathrm{NaCl}$ in the Atlantic Ocean and a concentrated solution of $\mathrm{KOH}(0.083 \mathrm{~mol} / \mathrm{l})$ and $\mathrm{NaOH}$ $(0.025 \mathrm{~mol} / \mathrm{l})$ to obtain a $\mathrm{pH}$ closed to that of the interstitial pore solution to avoid leaching of concrete. The samples are weighed weekly to constant mass. The immersion stage lasted four months.

The fourth sample (S4) is submerged four months too in another container filled with demineralised water loaded with $\mathrm{KOH}(0.083 \mathrm{~mol} / \mathrm{l})$ and $\mathrm{NaOH}(0.025 \mathrm{~mol} / \mathrm{l})$ only. S4 is used as a control sample to measure chloride content without chloride contamination.

\subsection{Procedure for obtaining total chloride content}

The well-known procedure recommended by the RILEM 178-TMC Technical Committee is used here. After exposure, the cylindrical cores are taken from the immersion tank to be ground in several steps of 4-mm each, perpendicular to the top faces of the cylinders using a grinding instrument. A 4-mm increment is chosen to obtain enough concrete powder for analysis by three operators. The powder is collected and stored in sealed plastic bags. This procedure recommended by Vennesland et al. (2012) does not use water. The grinding areas are larger than $40 \mathrm{~cm}^{2}$ (an 8 -cm diameter hole) to avoid excessive contribution from large aggregates.

The procedure described below is used to determine the total chloride content from concrete powder (Chaussadent and Arliguie 1999, RILEM TC 178-TMC 2002). Approximately 5g of concrete powder is taken from each layer and placed in a beaker. $\mathrm{HNO}_{3}$ and deionised water are added and the mixture is stirred and heated to $80^{\circ} \mathrm{C}$ for $30 \mathrm{~min}$. The solution is then filtered into a $250-\mathrm{cm}^{3}$ volumetric flask. The chloride concentration of the filtered solutions is determined by potentiometric titration using an automatic titrator with $0.01-\mathrm{M}$ silver nitrate $\left(\mathrm{AgNO}_{3}\right)$. 
All concrete specimens are ground in the same laboratory and by the same operator (called O2) while the others steps (filtration and titration) are conducted by different operators in two different laboratories for samples S1, S2 and S3. Four operators and two laboratories are then involved in the experimental program: $\mathrm{O} 1$ and $\mathrm{O} 2$ belonging to the same laboratory and $\mathrm{O} 3$ and $\mathrm{O} 4$ to the second laboratory. S2 and S3 samples are analysed twice by operator $\mathrm{O} 2$ (profiles indicated with brackets in Figure 1). These repetitive tests are carried out to quantify the error (cf. S96+ection 4). The different experimental steps and the corresponding operators are summarized in Table 3.

\subsection{Total chloride profiles}

Figure 1 presents nine total chloride profiles, which are supposed to be identical, and one total chloride profile for the specimen not contaminated with chloride (S4). Three profiles are provided for each sample immersed in chloride solution (S1, S2 and S3) to assess test errors on chloride determination. The nine profiles should be identical since the samples are made of the same concrete and contaminated with the same solution. They should also be horizontal (same content with depth) as the equilibrium is reached using the same sodium chloride solution. However, it is not. Therefore, the error is quantified in Section 4 using the information about this unexpected scattering.

With a cylinder length of $2.5 \mathrm{~cm}$, six points are expected for each profile. Yet since the concrete samples broke when the grinding instrument reached a depth of approximately $2 \mathrm{~cm}$, only five points have been obtained for samples S2 and S3 and four points only for sample S1. The error, therefore, will be calculated on 42 points.

The non-contaminated specimen S4 presents a profile with a non-zero concentration. The experimental mean content for S4, calculated using the five points obtained as a function of depth, is $2.6110^{-4} \mathrm{~kg} / \mathrm{kg}$ of concrete. It is related to the initial chloride content of the different concrete compounds: cement, filler, aggregates and water.

The chloride from the concrete components is calculated by considering the initial chloride content of each component given by the manufacturers (Table 4). The 10/14 aggregate material does not appear here because its initial chloride content is null. The apparent concrete density used to calculate the chloride content in $\mathrm{kg}$ of chloride by $\mathrm{kg}$ of concrete is 2293 $\mathrm{kg} / \mathrm{m}^{3}$. The value obtained is $2.5210^{-4} \mathrm{~kg} / \mathrm{kg}$ of concrete with the primary source of chloride, coming from sand. Indeed, the sand used here is extracted from sand mines in the Loire 
estuary. This value is close to the experimental value obtained with the profile $\left(2.6110^{-4}\right.$ $\mathrm{kg} / \mathrm{kg}$ of concrete).

\section{Error modelling}

\subsection{Modelling of measurement uncertainty}

Generally, measurement uncertainties are due to three main errors: protocol error $\mathrm{e}_{\mathrm{p}}$, sample error $\mathrm{e}_{\mathrm{s}}$ and human error $\mathrm{e}_{\mathrm{h}}$. The term "error" is purposely used in here because experimental results are compared with theoretical values.

The protocol error $e_{p}$ comes from all the uncertainties in devices and materials used throughout the experimental process (cf. Section 3.3). As regards the accuracy of the devices used for the measurements, the key factors are: the quality of the sample preparation (built in the laboratory or extracted on site), the quality of the testing devices. As regards measurement, it is a matter of quality of the post-treatment algorithm providing the output useful indicator. So, key factors involved here are: powder quality (powder fineness and heterogeneity), quality of the demineralised water and procedure for chloride extraction from concrete powder.

The error $\mathrm{e}_{\mathrm{s}}$ is due to the variability of the samples, which are assumed to be identical. Samples S1, S2 and S3 being saturated with the same solution and the chloride penetrating all the surfaces, the total chloride content should be the same and uniform for all the samples. However, this has not been experimentally verified and the profiles, which appear in Figure 1 show variability. This can be accounted for by the concrete heterogeneity even though the specimens are laboratory samples. In the case of concrete used for bridges in a marine environment, sampling under the same conditions provides some significantly different assessments of chloride ingress and service life predictions. These differences are probably due to concrete variations in areas assumed to be homogeneous (Goltermann 2004). This error is assessed by conducting a test of porosity measurement, for which all other uncertainties (protocol and human errors) are negligible. Porosity can be considered as the key-factor affecting chloride penetration into concrete. If porosities are similar, the specimens can be considered as homogeneous. The porosities studied here are assessed using the water saturation method (Table 5). The scattering of the porosity being weak, we can consider that the samples are similar. The scattering of the measurements between the samples is quantified below in order to analyse its impact in comparison with other uncertainties. 
The error $\mathrm{e}_{\mathrm{h}}$, called human factor, is caused by the operator. It mainly occurs in the course of the different non-automated sample preparation steps or when using the testing and measurement devices within predefined and normalized quality requirements (NF in France or $\mathrm{EN}$ in Europe). The error $\mathrm{e}_{\mathrm{h}}$ due to the operator usually occurs during solution filtration steps or when pipetting for titration dosing, which must be carried out very thoroughly. The human factor can be assessed after selecting the variability sources. Both, training (laboratory) and experience appear to be key-factors. Thus, four operators with different experience in two different laboratories have been selected. The tests have been carried out three times in the same laboratory using samples S2 and S3: twice by operator $\mathrm{O} 2$ and once by operator $\mathrm{O} 1$ who is an expert on this experimental procedure. Sample S1 has been analysed only once by operator $\mathrm{O} 2$ in order to save extra powder for the tests in the other laboratory (LNEC). These tests have been carried out by Operators $\mathrm{O} 3$ and O4. Test results are displayed in Table 6 and presented by profiles in Figure 1.

The three sources of uncertainties are considered to be independent and added up to obtain the total error:

$$
e_{t}=e_{p}+e_{s}+e_{h}
$$

The human error can lead, for instance, to the underestimation of the chloride content in a given sample in the case of a badly rinsed filter. In case of structure maintenance, an underestimation may mislead the manager and prompt a 'do nothing' decision although repair or protection is necessary. More generally, human errors do not lead systematically to the under or overestimation of the chloride content. Protocol error, however, leads to either over or underestimation. An overestimation leads to 'False Alarms' in terms of decision theory (Straub and Faber 2005; Rouhan and Schoefs 2003). Repair works are then planned when they are not fully needed, thus giving rise to additional costs.

\subsection{Data available for quantization of error}

The experimental campaign includes three samples (S1, S2 and S3) and four operators (O1, $\mathrm{O} 2$, O3 and O4) (Tables 3 and 6). Forty-two measurements have been performed with five points for each profile (Figure 1). According to the confidence interval of sampling theory, the statistical uncertainty due to a limited amount of data is quantified. If a conclusion can be drawn, then the available data are sufficient. Subsequently, we therefore show that the samples are adequate in quantity to demonstrate the main 
statistical properties and to quantify probability distribution statistical estimates. The chloride content as a function of the distance to the surface of the samples, which have a maximum length of $2.5 \mathrm{~cm}$, is presented in Figure 1. It can be recalled that all the surfaces of the cylindrical samples are in contact with the salt solution and that the specimens broke during the grinding step, thus reducing the profiles by $2 \mathrm{~cm}$. No significant trend between the samples is visible along the depth axis. This observation confirms that the samples are homogeneous (no depth effect) and that each measurement carried out on a sample at different depths can be considered as a repetitively test, i.,e., a test with the same concrete in the same conditions. Operators $\mathrm{O} 1, \mathrm{O} 2$, on the one hand and $\mathrm{O} 3, \mathrm{O} 4$, on the other hand, have worked in their respective laboratory and used the same devices and products.

When considering the three previous errors, the data are used as follows:

- protocol error: The tests performed on the control sample S4 can be used to quantify part of the protocol error. The measurements carried out by $\mathrm{O} 2$, twice on $\mathrm{S} 2$ and $\mathrm{S} 3$ can also be used to quantify the protocol error because a single operator followed the same protocol.

- sample error: The data from operator $\mathrm{O} 2$ are used to quantify the effect of the heterogeneity of samples because that same operator did all the measurements on S1, S2 and S3.

- human error: The operator influence is analysed by comparing the results obtained with Sample 1 because three different operators O2, O3 and O4 carried out measurements on S1.

\section{Results}

\subsection{Probabilistic modelling}

A probabilistic method is used to model uncertainties. The error is modelled using some random variables obtained from forty-two values. If insufficient information is available, other methods can be applied: interval theory and fuzzy logic (Möller and Beer 2008). A probabilistic 3-D space is considered based on the assumption that $\mathrm{e}_{\mathrm{p}}, \mathrm{e}_{\mathrm{s}}$ and $\mathrm{e}_{\mathrm{h}}$ are independent random variables. From a theoretical point of view, this assumption is acceptable because the nature of the errors is different. From a statistical point of view, the limited amount of data cannot be used to investigate deeper this property using a factorial analysis (this may require further dedicated examination). Moreover, due to the under or 
overestimations of the chloride content (cf. Section 4.1), the total error is modelled by adding a bias $b$ and a zero mean variable $\varepsilon$, as:

$$
e_{t}=b+\varepsilon
$$

The bias is defined by:

$$
\mathrm{b}=\bar{e}-\mathrm{C}^{\mathrm{r}}
$$

with $C^{r}$ : the reference chloride content value (assumed to be the real value);

$\bar{e}:$ the mean error, which is the average of the measured value $\hat{C}$.

We note that $C^{r}$ is:

- very close to 0 in the reference sample $\mathrm{S} 4$;

- calculated for samples S1, S2 and S3 using the concrete porosities and the supposed chloride binding capacity. When the equilibrium is reached, the concrete solution within porosity is supposed to be concentrated in chloride to a volume of $30 \mathrm{~g} / \mathrm{l}$. This allows for the calculation of the free chloride content in $\mathrm{kg} / \mathrm{kg}$ of concrete for each sample by taking porosity values displays in Table 5 into account. The chloride binding capacity used here has been found in the literature (Francy and Francois 1998) on mortars casted using the same cement. This information permits the evaluation of the supposedly bound chloride content. Free, bound and total chloride contents are summarized in Table 7. The discrepancy observed between the maximum (S1) and the minimum (S3) values is only $0.0810^{-3} \mathrm{~kg} / \mathrm{kg}$ of concrete.

The fact that $C^{r}$ is subjected to the condition ' $C$ r $\geq 0$ ', we obtain the condition: $b+\bar{e} \geq 0$.

\section{Assessment of bias b:}

Each component of $e_{t}$, starting with the protocol error, is now examined. Table 8 shows the values of $\mathrm{C}, \bar{e}$ and $\mathrm{b}$ for $\mathrm{S} 4$. Although sample $\mathrm{S} 4$ is assumed to be free of chlorides, detection is made. This part of the protocol error is modelled using a deterministic bias, called $b_{p}$. The bias is calculated as the mean value of the five chloride measurements carried out on sample S4. We obtain:

$$
\mathrm{b}_{\mathrm{p}}=0.2610^{-3}(\mathrm{~kg} / \mathrm{kg} \text { of concrete })
$$

Sample S1, for which the bias includes the bias due both to operator and protocol is now considered. The results of all the operators are used. However, because only four measurements are available for each operator, it is not sufficient to highlight a significant difference between operators. Moreover, the results show a weak scatter of the standard 
deviation between $0.1210^{-3}$ for $\mathrm{O} 2$ and $\mathrm{O} 3$, and $0.1910^{-3}$ for $\mathrm{O} 4$ but, since the $95 \%$ confidence interval around a theoretical value of $0.1510^{-3}$ for four measurements is $\left[0.08510^{-}\right.$ ${ }^{3}, 0.5610^{-3}$ ], the scatter is considered negligible. Therefore, no significant correlation between the standard deviation and the operator experience or laboratory is found. They are considered as independent events of the same variable. Consequently, all the data obtained by the operators are gathered. Then, the global standard deviation of $\varepsilon$ is $0.1410^{-3}$ and the coefficient of variation is approximately $9 \%$. The bias $b_{1}$ (notation of bias for $\mathrm{S} 1$ ) is the sum of the protocol plus human factor biases and is obtained from Equation (6). The result (-0.4 $10^{-3}$ $(\mathrm{kg} / \mathrm{kg}$ of concrete $))$ is reported in Table 8, where sign '-', for b, denotes an overestimation of the total chloride content.

Assuming that protocol gives a bias $b_{\mathrm{p}}$ of $0.2610^{-3}\left(\mathrm{~kg} / \mathrm{kg}\right.$ of concrete), the bias $b_{\mathrm{h}}$ due to the operator reaches $-0.6610^{-3}$ as:

$$
b_{h}=b_{1}-b_{p}=\left(b_{h}+b_{p}\right)-b_{p}=\left(-0.410^{-3}\right)-\left(0.2610^{-3}\right)=-0.6610^{-3}(\mathrm{~kg} / \mathrm{kg} \text { of concrete })
$$

The other samples, whose results increase the size of the database (Table 6: 12 to 15 tests) are finally considered. The accuracy of the bias assessment is improved. Knowing the theoretical value of $C^{r}$ for each sample, the values obtained with the three samples for $b_{i}$ and $\bar{e}_{i}$ (i denotes the sample number) are computed and presented in Table 9. The discrepancies among the three biases are very small and stand within the range $-0.410^{-3}$ and $-0.310^{-3}$. The statistical assessment error from twelve measurements, on the other hand, provides a 95\% confidence interval of $\left[-0.4210^{-3} ;-0.3110^{-3}\right]$. The bias mean value is selected and considered subsequently as the average value: $-0.3710^{-3}$.

We thus obtain: $b=-0.3710^{-3}(\mathrm{~kg} / \mathrm{kg}$ concrete $) ; b_{\mathrm{p}}=0.2610^{-3}(\mathrm{~kg} / \mathrm{kg}$ of concrete $) ; b_{\mathrm{h}}=-0.66$ $10^{-3}(\mathrm{~kg} / \mathrm{kg}$ of concrete $)$

\section{Assessment of the zero mean error $\varepsilon$ :}

The measurement error $\varepsilon$ is now assessed. As underlined, the gathering of the results obtained by different operators makes it possible to analyze the effect of the material heterogeneity using a larger number of tests (Table 6: 12 to 15 tests). For each sample, scattering includes errors due both to operator and protocol. On the basis of the value of $b$ (Table 9), the sample of $\varepsilon$ is obtained from Equation 5. The standard deviation of $\varepsilon$ is $0.1410^{-3}$ for samples $S 1$ and S2 and $0.0710^{-3}$ for sample S3, respectively. The coefficients of variation are $9 \%, 8 \%$ and $4 \%$ for samples S1, S2 and S3, respectively. 
This discrepancy is small considering the small amount of data available (12 or 15) because the width of the $95 \%$ confidence intervals for the standard variation ranges between $0.0610^{-3}$ and $0.1210^{-3}$. The $95 \%$ confidence intervals are $\left[0.110^{-3} ; 0.2410^{-3}\right],\left[0.0910^{-3} ; 0.2110^{-3}\right]$ and $\left[0.04710^{-3} ; 0.110^{-3}\right]$ for S1, S2, S3, respectively. This result confirms the findings in Section 4.1 about $\mathrm{e}_{\mathrm{s}}$ : the heterogeneity of this test is not a key factor in interpreting both bias and scatter. The error modelling is then obtained by gathering the forty-two tests. The standard deviation is then $0.1210^{-3}$ with a higher confidence whereas the $95 \%$ confidence interval is reduced to $\left[0.110^{-3} ; 0.1610^{-3}\right]$. We note that a different reference value is considered for each sample by using the bias in Table 8 and when computing zero mean error. The $\varepsilon$ distribution is given in Figure 2 from forty-two values. The zero-mean distribution is not symmetrical. The classical assumptions on error distributions, normal or uniform (Sheils et al. 2012) are not suitable here. Using the maximum likelihood estimates (MLE) of parameters (Jöreskog 1967) for fitting the error distribution using a probability density function (pdf), a comparison between three pdf is carried out. Generalized Extreme Value (GEV), Student and Normal. The GEV is selected because of its non-symmetrical shape whereas Student and Normal are usually considered for modelling error of measurements. Maximum likelihood estimation results (log likelihood) are given in Table 10. The maximum value of MLE is obtained for GEV pdf whose expression is given in Equation (9). As shown in Figure 2, good fit to the distribution of experimental data and compliance with the asymmetry is provided. This pdf, therefore, proves to be the best choice. Its parameters (scale, shape and location parameters, respectively) are: $\left[\mathrm{K}=0.016 ; \sigma=9.310^{-5} ; \mu=-8.410^{-5}\right]$. Here, $\mathrm{K}>0$ and GEV is called type II, or Frechet, extreme value distribution (Kotz and Nadarajah 2001). We obtain:

$$
f(x)=\frac{1}{\sigma}(1+K z)^{(-1-1 / K)} \exp \left(-(1+K z)^{(-1 / K)}\right)
$$

with $\quad z=\frac{x-\mu}{\sigma}$

Analysis results are compared using a probabilistic model. The error directly calculated from the statistical results is obtained as the difference between the measured value $\hat{C}$ and the reference value as:

$$
\mathrm{e}_{\mathrm{t}}=\hat{C}-\mathrm{C}^{\mathrm{r}}
$$


The experimental distribution is plotted (with bars) and fitted with an extreme value (EV) pdf (in dashed line) in Figure 3. Modelling, on the other hand, assumes that the error $\mathrm{e}_{\mathrm{t}}$ is the addition of the bias $\left(0.3710^{-3}\right)$ and the zero mean error $\varepsilon$ according to a GEV with the above parameters. We find:

$$
\mathrm{e}_{\mathrm{t}}=\varepsilon-0.3710^{-3}(\mathrm{~kg} / \mathrm{kg} \text { of concrete })
$$

A comparison of this model with the real distribution of error is carried out by adding the distribution curve obtained from the model in Figure 3 (full line). The model results appear to be consistent with the experimental data. This is the first time that the bias is identified and quantified and that the error is modelled with a non-symmetrical (GEV) pdf. This contribution will help to introduce a real model for maintenance updating and semidestructive testing optimization and to quantify the benefit over Non Destructive Testing.

\subsection{Effect on the probability of chloride detection}

When considering the corrosion of steel bars, two different probabilistic approaches are possible. The first one considers the corrosion as a stochastic process and aims to assess the probability of corrosion time (Mori and Ellingwood 1993; Sheils et al. 2012). The second approach is considered here. Its objective is to assess the probability of failure (Equation 2). In reliability analysis of reinforced concrete, it is generally computed as the probability that the residual steel area $A_{r, s}$ can be lower than a critical area $A_{\text {crit }}$ at time t. The critical area is either the percentage of acceptable loss of steel or the minimum area required to fulfill service or else the ultimate limit state of a structural component. The probability of failure is therefore expressed as:

$$
\mathrm{P}\left(\mathrm{A}_{\mathrm{r}, \mathrm{s}}(\mathrm{t})<\mathrm{A}_{\text {crit }}\right)=\mathrm{P}\left(\mathrm{A}_{\mathrm{r}, \mathrm{S}}(\mathrm{t})<\mathrm{A}_{\text {crit }} \mid \mathrm{C}>\mathrm{C}_{\text {crit }}\right) . \mathrm{P}\left(\mathrm{C}>\mathrm{C}_{\text {crit }}\right)
$$

The probability of systematic failure is called instantaneous probability of failure. Assume $\mathrm{C}_{\text {crit }}$ is a deterministic critical chloride content, called detection threshold in the literature, that we want to detect. In this paper, it is considered as deterministic to avoid the introduction of an additional random variable and to focus on the analysis of the effect of the uncertainty of measurement. NF EN 206-1 standard suggests that the limit content of chloride ions by weight of cement be taken as $0.4 \%$ (NF-EN 206-1 2000), which represents $0.0005 \mathrm{~kg} / \mathrm{kg}$ of concrete when considering the cement content. This value is the same than that used by 
Goltermann (2004). We then define PGA-CI (Probability of Good Assessment of Corrosion Initiation-see (3)) as:

$$
\text { PGA-CI }=\mathrm{P}\left(\mathrm{C}+\mathrm{e}_{\mathrm{t}}>\mathrm{C}_{\text {crit }} \mid \mathrm{C}>\mathrm{C}_{\text {crit }}\right)
$$

where $e_{t}$ is defined in (5) and $C$ is the real value. This concept proves very useful for the riskbased maintenance of existing structures (Breysse et al. 2009). Then, Equation (13) becomes:

$$
\mathrm{P}\left(\mathrm{A}_{\mathrm{r}, \mathrm{s}}(\mathrm{t})<\mathrm{A}_{\text {crit }}\right)=\mathrm{P}\left(\mathrm{A}_{\mathrm{r}, \mathrm{s}}(\mathrm{t})<\mathrm{A}_{\text {crit }} \mid \mathrm{C}+\mathrm{e}_{\mathrm{t}}>\mathrm{C}_{\text {crit }}\right) . \mathrm{PGA}-\mathrm{CI} . \mathrm{P}\left(\mathrm{C}>\mathrm{C}_{\text {crit }}\right)
$$

If the model for $b$ and $\varepsilon$ is now know and by introducing Equation (5) into Equation (13), then the solution of the problem becomes:,

$$
\begin{aligned}
& \text { PGA-CI }(\mathrm{C})=\mathrm{P}\left(\mathrm{C}+\mathrm{b}+\varepsilon>\mathrm{C}_{\text {crit }} \mid \mathrm{C}>\mathrm{C}_{\text {crit }}\right) \\
& =\mathrm{P}\left(\mathrm{b}+\varepsilon>\mathrm{C}_{\text {crit }}-\mathrm{C} \mid \mathrm{C}-\mathrm{C}_{\text {crit }}>0\right)=\mathrm{b}+{\underset{C}{C} C_{C_{\text {cit }}>0}}^{+} f(x) d x
\end{aligned}
$$

Figure 4 presents the evolution of PGA-CI with $\mathrm{C}_{\text {crit }} \mathrm{C}$. The probability of detection of a chloride content of 0.0006 reaches $87 \%$. C- $\mathrm{C}_{\text {crit }}=0.0001$ is represented by the coordinate point $(0.0001,0.8667)$ in Figure 4 . We can conclude that the result is highly dependent on the value of the critical chloride content, which is a deterministic value here. This value is deeply dependant on the type of concrete and could be used as a probabilistic value in the future.

\section{Conclusions and future}

In marine or de-icing salt environments, chloride concentration is the main input factor considered by concrete structure operators in the decision chain. The chloride concentration value is currently the only rational decision aid-tool for repair strategies and planning of future control campaigns. However, the reliability of the measured values must be discussed and quantified to provide a truly rational decision aid-tool for repair or inspection planning. In order to address this problem, the determination of measurement errors on chloride concentration is the key factor. Errors depend mainly on the different steps of the protocol: grinding, preparation of powder, acid attack, dilution, concentration measurements.

The paper addresses the problem by examining chloride concentration measurements in saturated samples carried out by four operators from two different laboratories. The three samples being saturated with the same solution and the chloride penetrating all the surfaces, the total chloride content should be the same and uniform with depth. 
The forty-two chloride content measurements are analysed in order to assess the total measurement error by considering three main errors (protocol error ep, sample error es and human error eh). The total measurement error is modelled using a bias and a zero mean error, well fitted by the Generalized Extreme Value probability density function. A value of the bias is also provided. Finally, the model results satisfactorily agree with the experimental results showing an unusual model: bias and non-symmetrical probability density function.

The probability of detection of corrosion initiation is then assessed as a function of the margin between the critical concentration and the real concentration. We observe that if this margin does not exceed 0.0001 (by weight of concrete), the probability of detection is less than $86 \%$. This lack of information will affect the decision of action by generating non-optimal (generally curative) maintenance or repair works. In order to improve our understanding and quantify the impact of assessment error in relation to perfect assessment, the modelled error discussed here can be introduced in the chloride ingress model as an additive variable. The propagation of this error with time will, indeed, altered the intervention dates of maintenance and repair actions. These timing changes will involve extra costs that will be quantified by undertaking a Life-Cycle-Cost analysis. The updating of probabilistic time-dependent degradation models with semi-destructive testing will be a challenge in the future with a key question: should the model be updated with a random variable that included significant error of measurement or should its use be limited to decision at a given time?

\section{Acknowledgements}

This study has been conducted within the context of a double research programme: the MEDACHS project (2005-2008) "Marine environment damage to Atlantic coast historical and transport structures and buildings: methods of assessment and repair, maintenance") and the DuratiNet project (2009-2014) "Network durable transport infrastructure in the Atlantic area "). Funds were provided by grants from ERDF for the European Union, program Interreg III B and supplemented by funds provided through the French project MAREO (20072012) "MAintenance and REpair of concrete coastal structures: risk based Optimization", thanks to which this research has been conducted under better conditions.

\section{References}

Ahmad S (2003) Reinforcement corrosion in concrete structures, its monitoring and service life prediction - a review. Cem Conc Comp $25: 459-71$ 
Atkings C-P, Carter M-A, Scantlebury J-D (2001) Sources of error in using silver/silver chloride electrodes to monitor chloride activity in concrete. Cem Conc Res 31:1207-11

Ang A-H-S, Tang W-H (1978) Probability: Basic Principles v. 1: Concepts in Engineering, Planning and Design. Book : ISBN-10: 0471035262

Balayssac J.P., Laurens S., Klysz G., Lataste J.F., Dérobert X. (2011), Non destructive evaluation of concrete contamination by chloride, European Journal of Environmental and Civil Engineering 15 (7): 1076-1084, DOI: 10.1080/19648189.2011.9695294.

Bastidas-Arteaga E, Schoefs F (2012) Stochastic improvement of inspection and maintenance of corroding reinforced concrete structures. Engineering Structures 41: 50-62

Ben Fraj A, Bonnet S, Khelidj A (2012) New approach for coupled chloride/moisture transport in non-saturated concrete with and without slag. Constr Build Mater 35: 761-771

Bermudez Odriozola M-A, Alaejos Gutierrez P (2008) Comparative study of different test methods for reinforced concrete durability assessment in marine environment. Mater Struct 41: 527-541

Castro P, De Rincon O-T, Pazini E-J (2001) Interpretation of chloride profiles from concrete exposed to tropical marine environments. Cem Conc Res 31: 529-537

Chaussadent T, Arliguie G (1999) AFREM test procedures concerning chlorides in concrete: extraction and titration methods. Mater Struct 32: 230-234

Costa A, Appleton J (1999) Chloride penetration into concrete in marine environment - Part I: Main parameters affecting chloride penetration. Mater Struct 32: 252-259

Deby F, Carcasses M, Sellier A (2009) Toward a probabilistic design of reinforced concrete durability: application to a marine environment. Mater Struct 42: 1379-1391

Der Kiureghian A, Ditlevsen O-D (2009) Aleatoric or epistemic? Does it matter? Structural Safety 31(2): 105112

Djerbi A, Bonnet S, Khelidj A, Baroghel-Bouny V (2008) Influence of traversing crack on chloride diffusion into concrete. Cem Conc Res 38:877-883

Faber M-H, Sorensen J-D (2002) Indicators for inspection and maintenance planning of concrete structures. Journal of Structural Safety 24(4): 377-396

Francy O, Francois R (1998) Measuring chloride diffusion coefficients from non steady-steady state diffusion test. 28 (7): Cem Conc Res 32: 947-953

Goltermann P (2004) Variation of chloride profiles in homogeneous areas. Mater Struct 37: 608-614

Jöreskog K-G (1967) Some Contributions to Maximum Likelihood Analysis. Psychometrika 32: 443-482.

Kirkpatrick T-J, Weyers R-E, Anderson-Cook C-M, Sprinkel M-M (2002) Probabilistic model for the chlorideinduced corrosion service life of bridge decks. Cem Conc Res 32: 1943-1960

Kong JS, Ababneh AN, Frangopol DM, Xi Y. Reliability analysis of chloride penetration in saturated concrete. Probab Eng Mech 2002;17:305-15.

Kotz S, Nadarajah S (2001) Extreme Value Distributions: Theory and Applications. World Scientific Publishing Company

Lecieux Y., Schoefs F., Bonnet S., Lecieux T., Palma Lopez S. Quantification and uncertainty analysis of a structural monitoring device: detection of chloride in concrete using DC electrical resistivity measurement, Non destructive Testing and Evaluation, Vol 30 issue 3, Pages 216-232, May 2015. 
Liang M-T., Lan J-J (2005) Reliability analysis for the existing reinforced concrete pile corrosion of bridge structure. Cem Conc Res 35: 540-550

Lindvall A (2007) Chloride ingress data from field and laboratory exposure - Influence of salinity and temperature. Cem Conc Comp 29: 88-93

Marques P-F, Costa A, Lanata F (2012) Service life of RC structures: chloride induced corrosion: prescriptive versus performance-based methodologies. Mater Struct 45: 277-296

Montemor M-F, Simoes A-M-P, Ferreira M-G-S (2003) Chloride-induced corrosion on reinforcing steel: from the fundamentals to the monitoring techniques. Cem Conc Comp 25: 491-502.

Montemor M-F, Alves J-H, Simoes A-M, Fernandes J-C-S, Lourenço, Costa A-J-S, Appleton A-J, Ferreira MG-S (2006) Multiprobe chloride sensor for in situ monitoring of reinforced concrete structures. Cem Conc Comp $28: 233-236$

Mori Y, Ellingwood B (1993) Reliability-based service life assessment of aging concrete structures. ASCE J of Struct Engr 119(5):1600-1621

NF-EN 206-1, P18-325 (2012) Concrete - Part 1: specification, performance, production and conformity. AFNOR editions

Reddy B, Glass G-K, Lim P-J, Buenfeld N-R (2002), On the corrosion risk presented by chloride bound in concrete. Cem Conc Comp 24: 1-5

RILEM TC 178-TMC (2002), Recommendation for analysis of total chloride in concrete. Mat Struct 35: 583585

Rosquoët F, Bonnet S, Schoefs F, Khelidj A (2006) Chloride propagation in concrete harbour structure. International RILEM conference on Advances in Concrete through Science and Engineering, Québec (Canada)

Rouhan A, Schoefs F (2003) Probabilistic modelling of inspection results for offshore structures. Journal of Structural Safety 25(4): 379-399

Sheils E, O'Connor A, Breysse D, Schoefs F, Yotte S (2010) Development of a two stage inspection process for the assessment of deteriorating bridge structures. Reliability Engineering and System Safety 95(3): 182-194

Sheils E, O'Connor A, Schoefs F, Breysse D (2012) Investigation of the Effect of the Quality of Inspection Techniques on the Optimal Inspection Interval for Structures. Structure and Infrastructure Engineering: Maintenance, Management, Life-Cycle Design and performance (NSIE) 8( 6/June 2012): 557-568

Silva N, Luping T, Rauch S (2012) Application of LA-ICP-MS for meso-scale chloride profiling in concrete. Mater Struct. DOI 10.1617/s11527-012-9979-y

Sosdean C.,Marsavina L., De Schutter G. (2016) Experimental and numerical determination of the chloride penetration in cracked mortar specimens, European Journal of Environmental and Civil Engineering 20 (issue 2): 231-249, doi:10.1080/19648189.2015.1035802

Standard test method for acid-soluble chloride in mortar and concrete: ASTM C1152M - 04; 2006.

Stipanovic Oslakovic I, Bjegovic D, Mikulic D (2010) Evaluation of service life design models on concrete structures exposed to marine environment. Mater Struct 43: 1397-1412

Straub D, Faber M-H (2005) Risk based inspection planning for structural systems. Structural safety 27(4): 335355 
Torres-Luque M, Bastidas-Arteaga E. Schoefs F, Sanchez-Silva M, Osma J-F (2014) Non-destructive methods for measuring chloride ingress into concrete: State-of-the-art and future challenges", Construction and Building Materials, 68/15: 68-81, doi: 10.1016/j.conbuildmat.2014.06.009

Tuutti K., Corrosion of steel in concrete. Swedish Cement and Concrete Research Institute; 1982. <http://www.lunduniversity.lu.se/o.o.i.s?id=12683\&postid=3173286>.

Val DV, Trapper PA., Probabilistic evaluation of initiation time of chlorideinduced corrosion. Reliab Eng Sys Safety 2008;93:364-72.

Vennesland $\varnothing$, Climent M-A, Andrade C (2012) Recommendation of RILEM TC 178-TMC: Testing and modelling chloride penetration in concrete. Methods for obtaining dust samples by means of grinding concrete in order to determine the chloride concentration profile. Mater Struct : RILEM Technical Committee

Wall H, Nilsson L-O (2008) A study on sampling methods for chloride profiles: simulations using data from EPMA. Mater Struct 41: 1275-1281

Yang L, Li K, Pang X (2012) Design and optimization of maintenance strategies for a long life-span port project Mater Struct. DOI 10.1617/s11527-012-9891-5 


\section{Modelling and quantization of measurement errors for chloride profile assessment \\ S. Bonnet*, F. Schoefs , M. Salta}

\section{List of Figures}

Figure 1. Total chloride profiles

Figure 2. Distribution of the zero mean error (epsilon) fitted with three pdf

Figure 3. Distribution of error (e) fitted with EV and compared with the model results (full line)

Figure 4. PoD-CI as a function of C-Ccrit

\section{List of Tables}


Table 1. Chemical composition of cement

Table 2. Ordinary Portland Concrete composition

Table 3. Operator experimental steps

Table 4. Initial chloride content provided by concrete components

Table 5. Open porosities measured by water saturation

Table 6. Available data (S: sample ; O: Operator)

Table 7. Free, bound and total chloride contents for samples S1, S2 and S3

Table 8. Values of bias due to bothhuman and protocol errors

Table 9. Values of bias in case of heterogeneous samples (sample error)

Table 10. Maximum likehood estimates (MLE) for three candidates

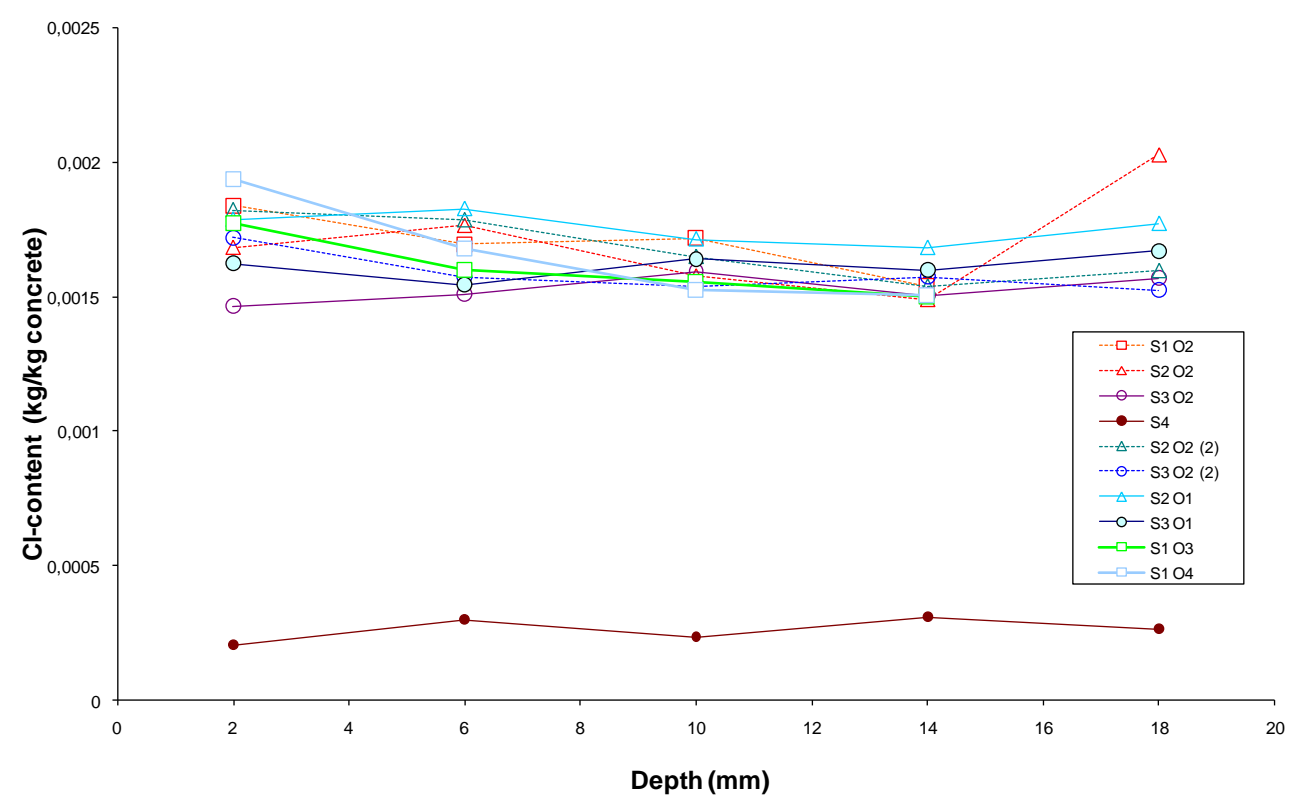

Figure 1. Total chloride profiles 


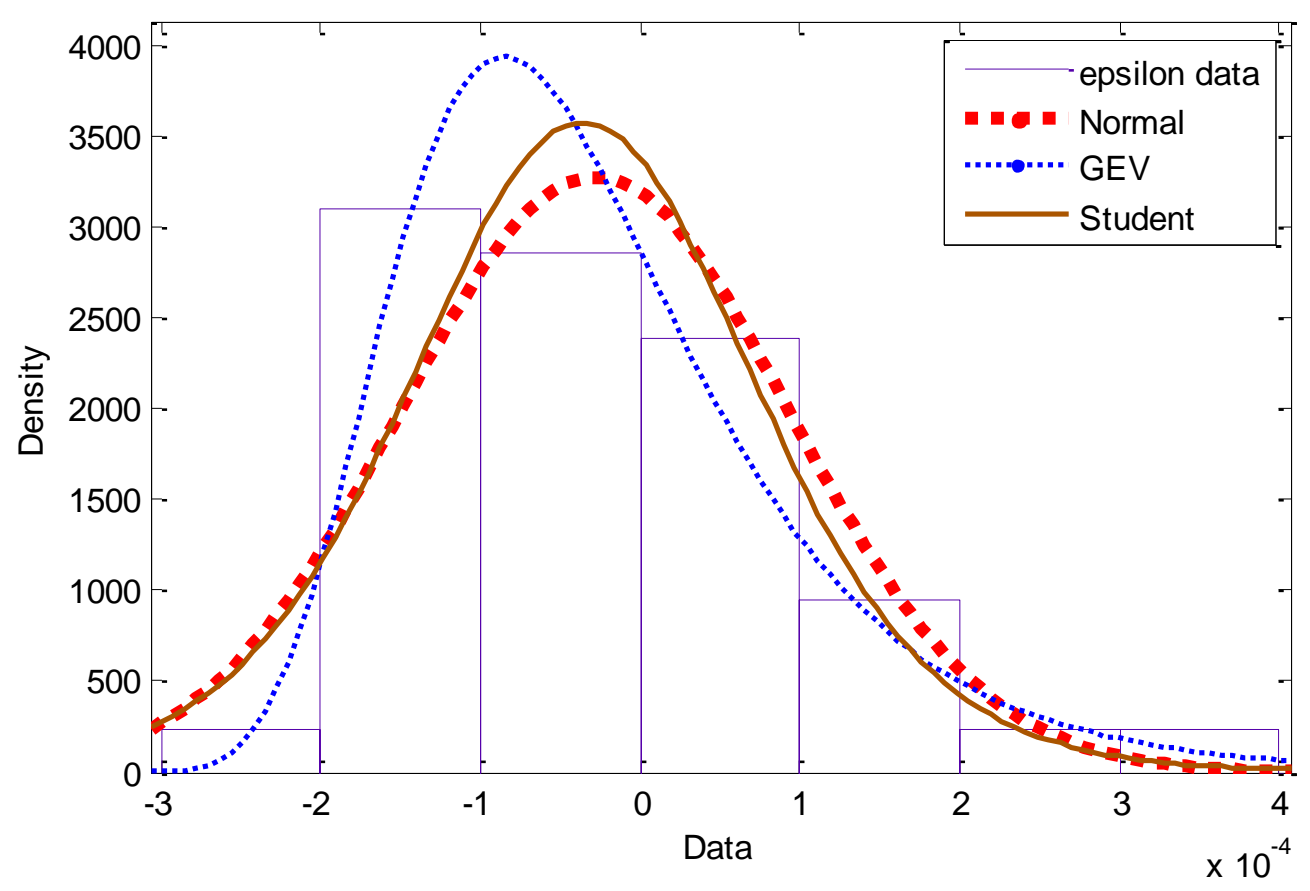

Figure 2. Distribution of the zero mean error (epsilon) fitted with three pdf

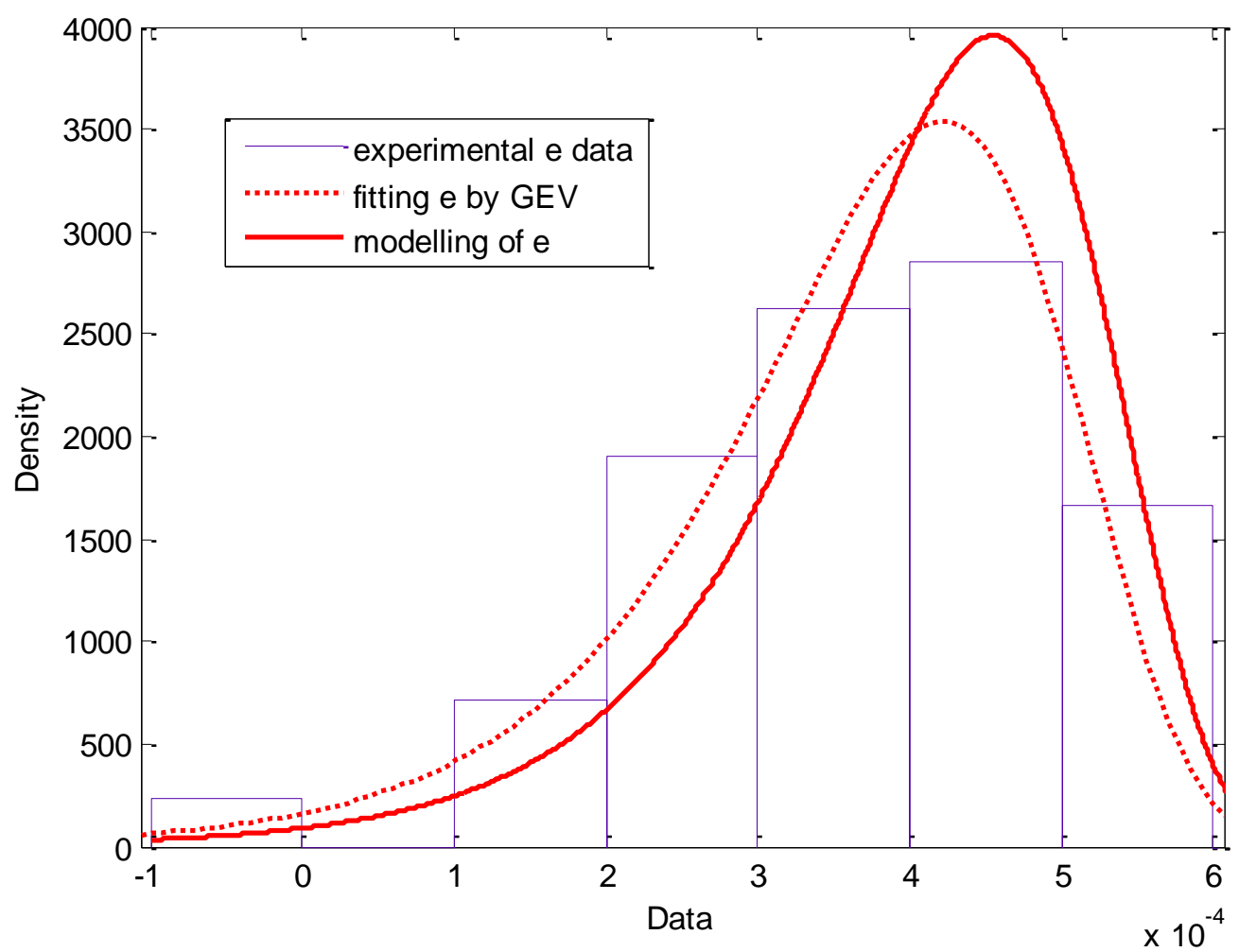

Figure 3. Distribution of error (e) fitted with EV and compared with model results (full line) 


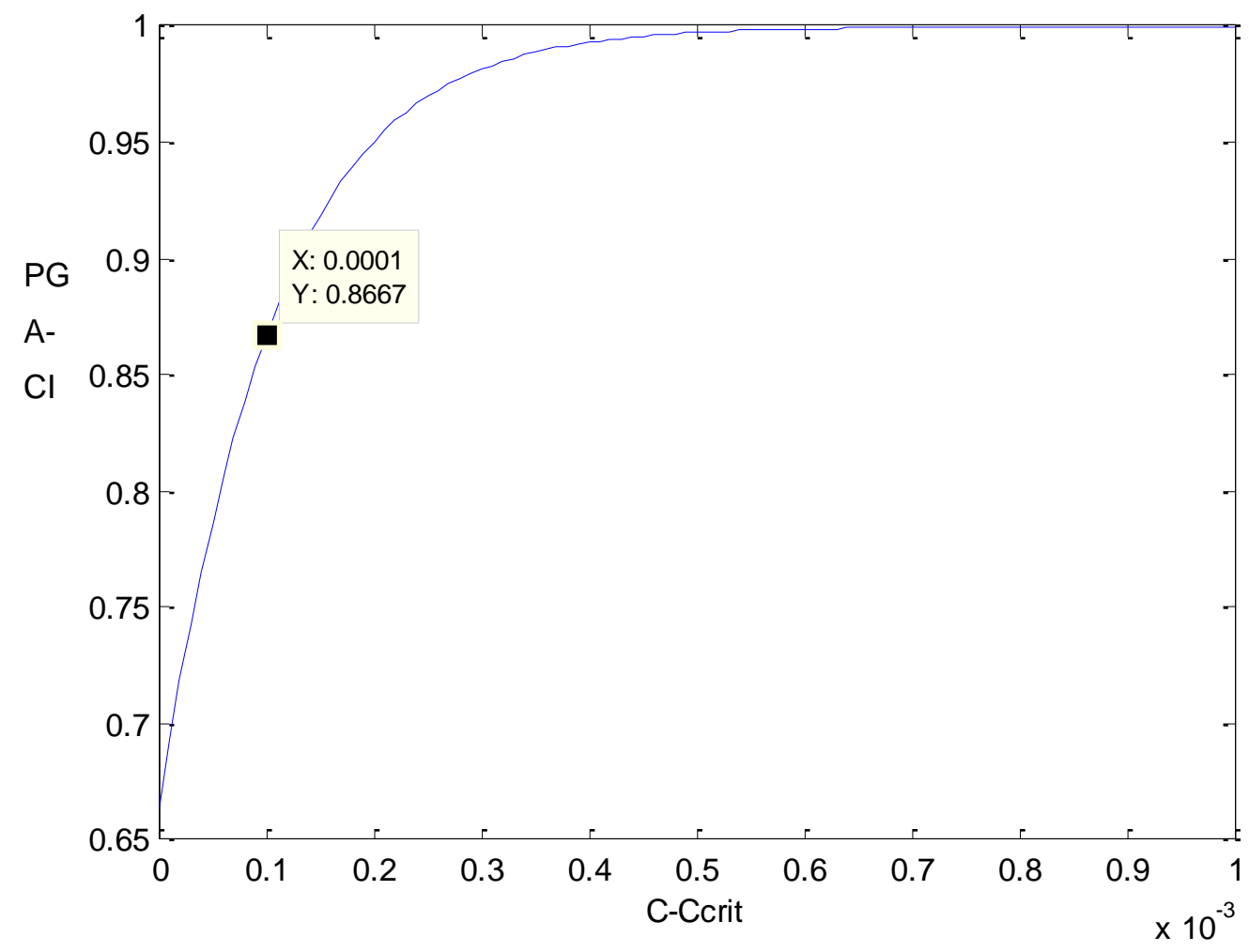

Figure 4. PGA-CI as a function of C-Ccrit 
Table 1. Chemical composition of cement

\begin{tabular}{lc}
\hline Compounds & mass \% \\
\hline $\mathrm{CaO}$ & 64.53 \\
$\mathrm{SiO} 2$ & 20.12 \\
$\mathrm{~A} 12 \mathrm{O} 3$ & 5.03 \\
$\mathrm{Fe} 2 \mathrm{O} 3$ & 3.12 \\
$\mathrm{MgO}$ & 0.98 \\
$\mathrm{~K} 2 \mathrm{O}$ & 0.98 \\
$\mathrm{Na} 2 \mathrm{O}$ & 0.16 \\
$\mathrm{SO} 3$ & 3.34 \\
$\mathrm{Specific}$ surface (m²/Kg) & 382 \\
Density (-) & 3.18 \\
Main compounds (Bogue's composition) mass\% & \\
$\mathrm{C} 3 \mathrm{~S}$ & 63.49 \\
$\mathrm{C} 2 \mathrm{~S}$ & 12.6 \\
$\mathrm{C} 3 \mathrm{~A}$ & 8.09 \\
C4AF & 9.8 \\
Gypsum & 4.5 \\
\hline
\end{tabular}


Table 2. Ordinary Portland Concrete composition

\begin{tabular}{lc}
\hline Compounds & $\begin{array}{c}\text { Mix } \\
\text { ingredients } \\
\left(\mathrm{kg} / \mathrm{m}^{3}\right)\end{array}$ \\
\hline Aggregate 10-14 mm & 887,1 \\
Sand (Loire) 0-4 mm & 852,8 \\
Cement CEM I 52.5 & 215,7 \\
Calcareous Filler & 161,4 \\
Total water & 176 \\
Water to binder ratio (W/B) & 0,47 \\
\hline
\end{tabular}


Table 3. Operators experimental steps

\begin{tabular}{ccccc}
\hline Sample & $\mathrm{S} 1$ & $\mathrm{~S} 2$ & $\mathrm{~S} 3$ & $\mathrm{~S} 4$ \\
\hline $\begin{array}{c}\text { Solution } \\
\text { immersion }\end{array}$ & $\mathrm{NaCl}=30 \mathrm{~g} / \mathrm{K}+\mathrm{NaCl}=30 \mathrm{~g} / \mathrm{NaOH}$ & $\mathrm{NaCl}=30 \mathrm{~g} / \mathrm{l}$ & $\mathrm{NaCl}=0 \mathrm{~g} / \mathrm{l}$ \\
\hline Grinding & $\mathrm{O} 2$ & $\mathrm{O} 2$ & $\mathrm{O} 2$ & $\mathrm{O} 2$ \\
\hline Filtration & $\mathrm{O} 2$ & $\mathrm{O} 1$ & $\mathrm{O} 1$ & $\mathrm{O} 2$ \\
+ Titration & $\mathrm{O} 3$ & $\mathrm{O} 2(2$ times $)$ & $\mathrm{O} 2(2$ times $)$ & \\
& $\mathrm{O} 4$ & & & \\
\hline
\end{tabular}


Table 4. Initial chloride content provided by concrete components

\begin{tabular}{ccccc}
\hline Compound & $\begin{array}{c}\text { Chloride } \\
\text { content } \\
\text { (from furnisher) }\end{array}$ & $\begin{array}{c}\text { Mix design } \\
\text { (kg of compound } / \mathrm{m}^{3} \text { of } \\
\text { concrete) }\end{array}$ & $\begin{array}{c}\text { Chloride } \\
(\mathrm{kg} \text { of chloride } \\
/ \mathrm{m}^{3} \text { of concrete) }\end{array}$ & $\begin{array}{c}\text { Chloride } \\
\text { (kg of chloride } \\
/ \mathrm{kg} \text { of concrete) }\end{array}$ \\
\hline Sand & $\begin{array}{c}0.065 \\
\text { (by weight) }\end{array}$ & 852.8 & 0.55432 & $2.41744 .10^{-4}$ \\
\hline Cement & $\begin{array}{c}0.01 \\
\text { \% (by weight) }\end{array}$ & 215.7 & 0.02157 & $0.09407 .10^{-4}$ \\
\hline Filler & 0.002 & 161.4 & 0.00323 & $0.01407 .10^{-4}$ \\
& $\%$ (by weight) & & & \\
\hline Tap water & $0,18.10^{-6}$ & 176 & 0.00003 & $0.00013 .10^{-4}$ \\
\hline Total & $(\mathrm{kg} / \mathrm{L})$ & & & $\mathbf{2 . 5 2 5 7 3 . 1 0}$ \\
\hline
\end{tabular}


Table 5. Open porosity measured by water saturation

\begin{tabular}{cccc}
\hline Sample & S1 & S2 & S3 \\
\hline Water porosity (\%) & 14.3 & 13.8 & 13.7 \\
\hline
\end{tabular}


Table 6. Available data (S: sample ; O: Operator)

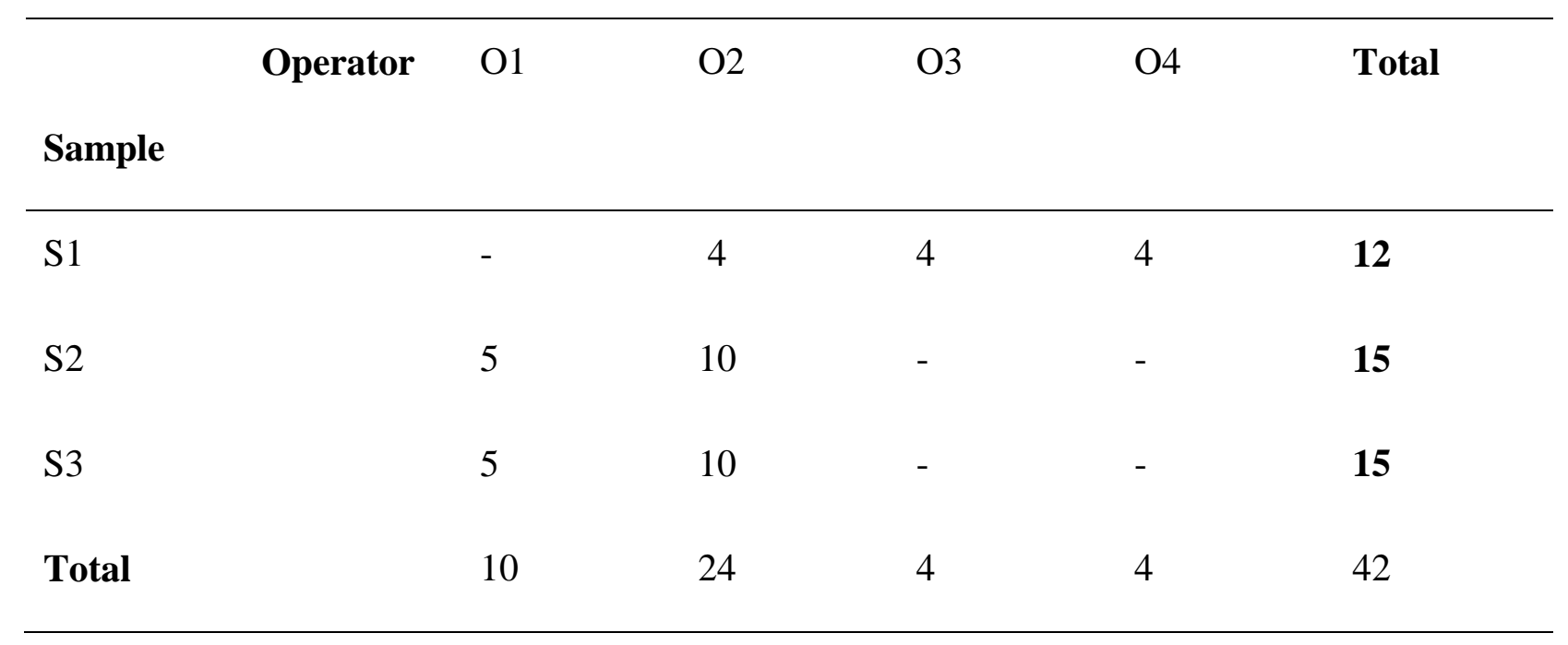


Table 7. Free, bound and total chloride contents for samples S1, S2 and S3

\begin{tabular}{cccc}
\hline & S1 & S2 & S3 \\
$\begin{array}{c}\text { Chloride content } \\
(\mathrm{kg} / \mathrm{kg} \text { of concrete })\end{array}$ & & & \\
\hline Free chloride & $1.8710^{-3}$ & $1.8110^{-3}$ & $1.7910^{-3}$ \\
Bound chloride & $0.1910^{-3}$ & $0.1910^{-3}$ & $0.1910^{-3}$ \\
Total chloride & $\mathbf{2 . 0 6} \mathbf{1 0}^{-3}$ & $\mathbf{2} \mathbf{1 0}^{-3}$ & $\mathbf{1 . 9 8 ~ \mathbf { 1 0 } ^ { - 3 }}$ \\
$\boldsymbol{C}^{\boldsymbol{r}}$ & & & \\
\hline
\end{tabular}


Table 8. Values of bias due to both human and protocol errors

\begin{tabular}{|c|c|c|c|}
\hline $\begin{array}{l}\text { Reference, } \\
\text { error and bias } \\
\text { (kg/kg of concrete) }\end{array}$ & $\begin{array}{c}\text { Source } \\
\text { of } \\
\text { error }\end{array}$ & $\begin{array}{l}\text { Protocol } \\
\qquad(\mathrm{S} 4)\end{array}$ & $\begin{array}{c}\text { Protocol + } \\
\text { Human factor } \\
(\mathrm{O} 1, \mathrm{O} 2, \mathrm{O} 3 \\
\text { for } \mathrm{S} 1)\end{array}$ \\
\hline$C^{r}$ & & 0 & $2.0610^{-3}$ \\
\hline $\bar{e}$ & & $0.2610^{-3}$ & $1.6610^{-3}$ \\
\hline b & & $0.2610^{-3}$ & $-0.4010^{-3}$ \\
\hline
\end{tabular}


Table 9. Values of bias in case of heterogeneous samples (sample error)

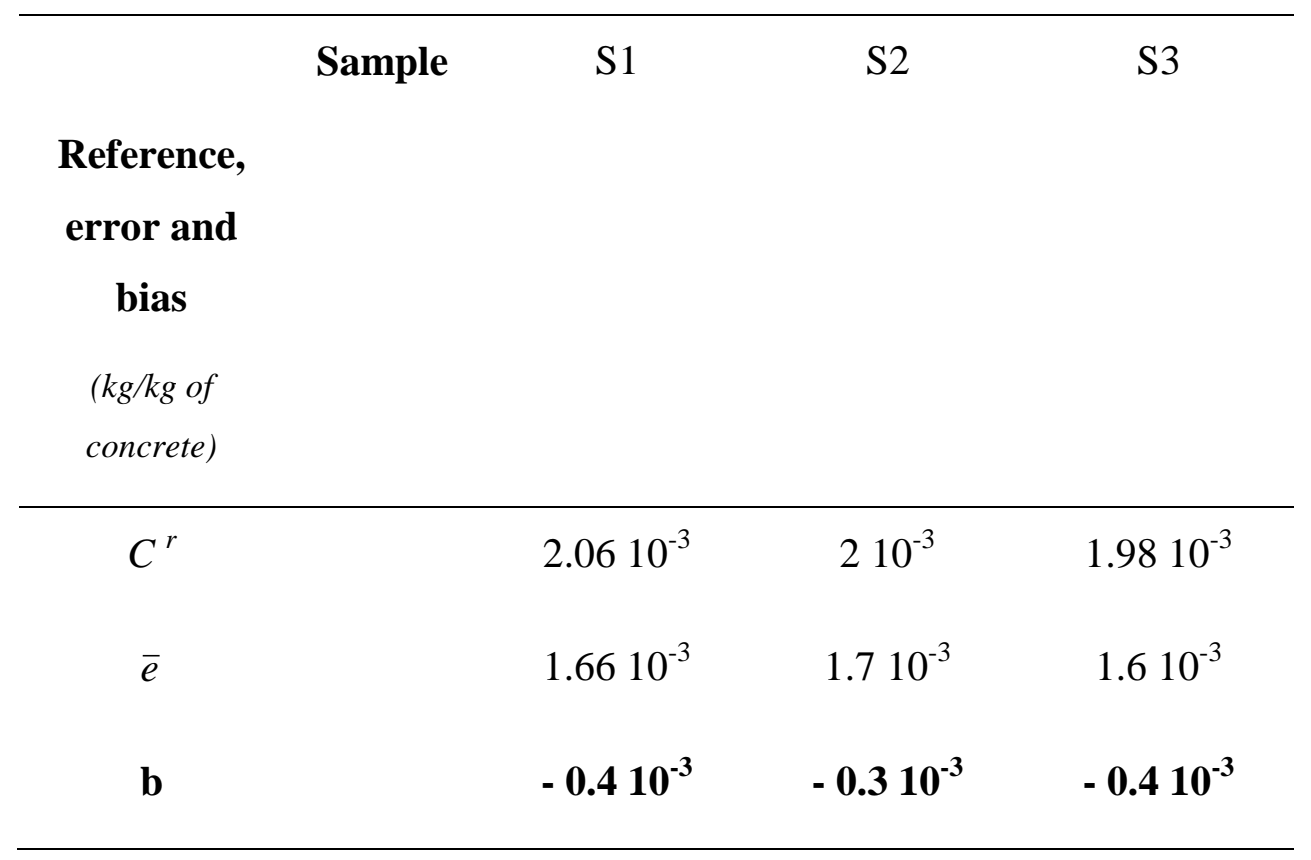


Table 10. Maximum likelihood estimates (MLE) for three pdf candidates

\begin{tabular}{llll}
\hline $\begin{array}{l}\text { Probability } \\
\text { density function }\end{array}$ & GEV & Normal & Student \\
\hline MLE & 323 & 319 & 320 \\
\hline
\end{tabular}

